\title{
Treat AIDS-Related Malignancies
}

National Cancer Institute

\section{Source}

National Cancer Institute. Treat AIDS-Related Malignancies. NCI Thesaurus. Code C19089.

Discover, develop, and evaluate improved strategies for the treatment and prevention of HIV-associated malignancies and extend our understanding of the risk factors for and pathogenesis of such malignancies. 